Fixed Point Theory, 22(2021), No. 2, 779-784

DOI: $10.24193 /$ fpt-ro.2021.2.50

http://www.math.ubbcluj.ro/ nodeacj/sfptcj.html

\title{
ESSENTIAL WEAKLY MÖNCH TYPE MAPS AND CONTINUATION THEORY
}

\author{
DONAL O'REGAN \\ School of Mathematics, Statistics and Applied Mathematics \\ National University of Ireland, Galway, Ireland \\ E-mail: donal.oregan@nuigalway.ie
}

Abstract. In this paper we present a variety of Leray-Schauder type continuation theorems for
general classes of weakly Mönch type maps.
Key Words and Phrases: Essential maps, fixed points, nonlinear alternatives, Mönch type maps.

2020 Mathematics Subject Classification: 47H10, 54H25, 55M20.

\section{REFERENCES}

[1] R.P. Agarwal, D. O'Regan, Continuation methods for closed, weakly closed, DKT and WDKT maps, Computers and Mathematics with Applications, 38(1999), 81-88.

[2] A. Ben Amar, M. Mnif, Leray-Schauder alternatives for weakly sequentially continuous mappings and applications to transport equations, Math. Methods Appl. Sci., 33(2010), 80-90.

[3] A. Ben Amar, D. O'Regan, Topological Fixed Point Theory for Singlevalued and Multivalued Mappings and Applications, Springer, Cham, 2016.

[4] T. Cardinali, D. O'Regan, P. Rubbioni, Mönch sets and fixed point theorems for multimaps in locally convex topological spaces, Fixed Point Theory, 18(2017), 147-153.

[5] A. Granas, Sur la méthode de continuité de Poincaré, C.R. Acad. Sci. Paris, 282(1976), 983-985.

[6] H. Mönch, Boundary value problems for nonlinear ordinary differential equations in Banach spaces, Nonlinear Anal., 4(1980), 985-999.

[7] D. O'Regan, Mönch type results for maps with weakly sequentially closed graphs, Dynamic Systems and Applications, 24(2015), 129-134.

[8] D. O'Regan, Maps with weakly sequentially closed graphs satisfying compactness conditions on countable sets, Pure and Applied Functional Analysis, 6(2021), 367-372.

[9] D. O'Regan, Coincidence results for compositions of multivalued maps based on countable compactness principles, Journal of Nonlinear and Convex Analysis, 21(2020), 543-549.

[10] D. O'Regan, R. Precup, Fixed point theorems for set-valued maps and existence principles for integral inclusions, J. Math. Anal. Appl., 245(2000), 594-612.

[11] D. O'Regan, R. Precup, Theorems of Leray-Schauder Type and Applications, Gordon and Breach Science Publishers, Amsterdam, 2001.

[12] W.V. Petryshyn, P.M. Fitzpatrick, A degree theory, fixed point theorems and mapping theorems for multivalued noncompact mappings, Trans. Amer. Math. Soc., 194(1974), 1-25.

[13] R. Precup, On the topological transversality principle, Nonlinear Anal., 20(1993), 1-9.

[14] M. Väth, Fixed point theorems and fixed point index for countable condensing maps, Topological Methods in Nonlinear Anal., 13(1999), 341-363. 
Received: June 12, 2019; Accepted: January 7, 2020. 